\title{
CRITICAL ILLNESS POLYNEUROPATHY IN CHILDREN WITH MENINGOCOCCAL INFECTION COMPLICATED WITH SEPSIS AND MENINGOCOCCEMIA
}

Voitenkov V.B., Vilnits A.A., Skripchenko N.V., Klimkin A.V. Pediatric Research and Clinical Center for Infectious Diseases, Saint-

Petersburg, Russia

Critical illness polyneuropathy (CIP) are complication of critical illness, generally affecting the motor and sensory

axons. It was first described by Bolton et al. in 1986 [Bolton et al., 1986]. This disorder can cause limb weakness and failure to wean from mechanical ventilation. CIP in childhood remains poorly investigated. Our aim was to investigate incidence, severity, clinical features, outcomes and conduction velocity findings in critically ill children with infectious diseases.
Study population: 70 children admitted to the ICU with meningococcal infection, all under mechanical ventilation. Among 70 patients 14 develop progressive symmetrical flaccid muscle weakness; deep tendon reflexes were reduced or absent; grimacing without movement with noxious stimuli also was noted; these children were suspected for CIP. After CIP was suspected, conduction nerve study of motor (median and common peroneal) and sensor (median and sural) nerves was performed.

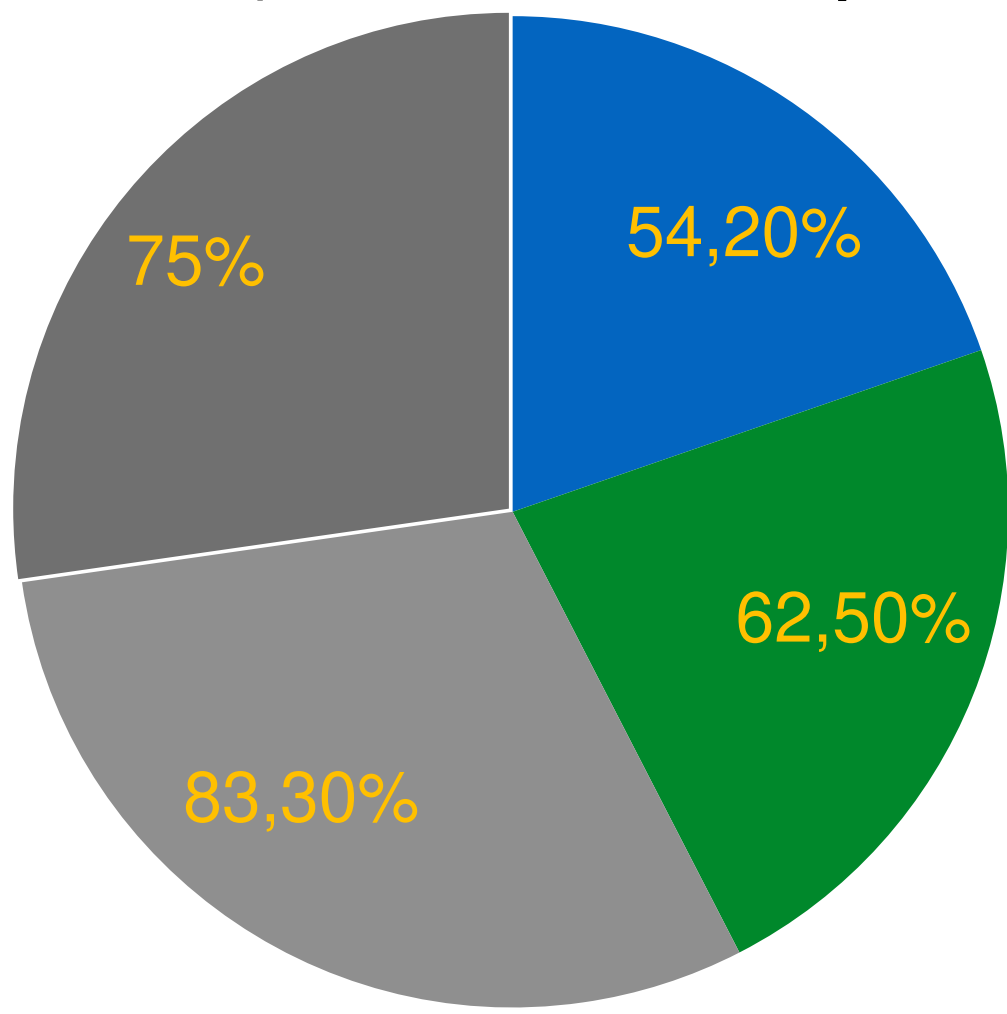

Electrophysiological signs of CIP occurred in 10 patients $(14,2 \%, 95 \% \mathrm{Cl} \%$ to \%). All 10 developed CIP within 12 days of ICU admission and 7 days of mechanical ventilation. Nerve conduction velocity was normal in all cases. Most pronounced drop in amplitudes of sensory responses was seen in common peroneal nerve. Among motor responses more often common peroneal nerve was affected. Among 10 patients with CIP in 6 cases (60\%) in next 21 days improvement in clinical signs and conduction studies were seen. 3 patients $(30 \%)$ at the moment of the discharge from ICU still had CIP signs. Percentage of affected nerves is presented on Figure 1.

Conclusions. CIP appear often in critically ill children with infectious diseases. Among 70 critically ill children in $\mathbf{1 4 , 2} \%$ CIP was diagnosed. In $\mathbf{7 0} \%$ of the cases its course was severe. 